\title{
Targeting tumor-associated macrophages in the tumor microenvironment (Review)
}

\author{
KAIWEN ZHOU ${ }^{1,2}$, TAN CHENG $^{3}$, JINYUE ZHAN $^{4}$, XUAN PENG $^{5}$, YUE ZHANG $^{5}$, \\ JIANPEI WEN $^{5}$, XIAOMAN CHEN $^{1}$ and MUYING YING ${ }^{1}$ \\ ${ }^{1}$ Department of Molecular Biology and Biochemistry, Basic Medical College of Nanchang University; \\ ${ }^{2}$ The First Clinical Medical College, School of Medicine, Nanchang University; \\ ${ }^{3}$ Queen Mary School of Nanchang University; ${ }^{4}$ School of Public Health; ${ }^{5}$ The Fourth Clinical Medical College, \\ School of Medicine, Nanchang University, Nanchang, Jiangxi 330006, P.R. China
}

Received September 11, 2019; Accepted June 23, 2020

DOI: $10.3892 / \mathrm{ol} .2020 .12097$

\begin{abstract}
Tumor-associated macrophages (TAMs) are the most abundant population type of tumor-infiltrating immune cells found in the tumor microenvironment (TME), and are evolutionarily associated with microvessel density in tumor tissues. TAMs can be broadly divided into M1-like and M2-like TAMs, which demonstrate antitumor and pro-tumor activity in the TME, respectively. Studies have indicated that: i) The predominate presence of M2-like TAMs in the TME can result in tumor immunosuppression and chemoresistance; ii) the ratio of M1-like to M2-like TAMs in the TME is positively correlated with better long-term prognosis of patients with cancer; iii) epigenetic silencing, preventing the secretion of M1-like TAM-associated molecules, is an important immune evasion mechanism during tumor progression; and iv) the transformation from M2-like to M1-like TAMs following exposure to specific conditions can result in tumor regression. The present study discusses the molecular events underlying the recruitment of macrophages and their polarization into M1-like or M2-like TAMs, and their differential roles in angiogenesis, angiostasis, invasion, metastasis and immune activity in the TME. This insight may inform the improved design of TAM-targeted cancer immunotherapy. Some of these therapeutic strategies show promising effects; however, challenges remain.
\end{abstract}

Correspondence to: Professor Muying Ying, Department of Molecular Biology and Biochemistry, Basic Medical College of Nanchang University, 461 Bayi Road, Nanchang, Jiangxi 330006, P.R. China

E-mail: yingmuying@ncu.edu.cn

Key words: tumor-associated macrophages, tumor-associated macrophage-targeted cancer immunotherapy, tumor-associated macrophage phenotypic characteristics, tumor-associated macrophage function characteristics, tumor microenvironment

\section{Contents}

1. Introduction

2. The recruitment of macrophages into the TME

3. The polarization of macrophages in the TME

4. Markers of M1-like TAMs and M2-like TAMs

5. TAMs functions in angiogenesis and angiostasis

6. TAMs functions in the invasion and metastasis of tumor cells

7. TAMs immune effects in the TME

8. Potential strategies for TAMs-targeted cancer immunotherapy

9. Conclusion

\section{Introduction}

Macrophages can directly engulf aberrant cells in normal or non-tumor disease conditions and are therefore conventionally regarded as anti-carcinogenesis (1). Due to their extremely plastic phenotypes and highly dynamic functions, macrophages can be transformed into different subtypes that have been reported to differentially regulate tumor progression in the tumor microenvironment (TME) (2). According to the similarities in gene expression patterns and functions between TAMs and traditional M1- and M2-type macrophages, TAMs with mixed phenotypes are broadly divided into M1-like and M2-like TAMs. M2 macrophages can be further subdivided into M2a, M2b, M2c and M2d subtypes in response to different inducers in the TME (3) (Fig. 1).

M2a macrophages, induced by interleukin (IL)-4 and IL-13, are characterized by the increased expression of mannose receptor CD206, decoy IL-1 receptor (IL-R) and C-C motif chemokine ligand (CCL)17 (4). M2a macrophages associated with wound healing can contribute to tissue repair by secreting pro-fibrotic factors, such as transforming growth factor (TGF)- $\beta$, insulin-like growth factor (IGF) and fibronectin (5) (Fig. 1). M2b macrophages induced by immune complexes (IC) and toll-like receptor (TLR)/IL-1R ligands are immune regulators (6). By inhibiting immune and inflammatory responses in cancer and infectious diseases, M2b can promote tumor development and parasite, bacterial and fungal 
infections (Fig. 1) (6). In addition, M2b can attenuate spinal cord injury and early reperfusion injury after myocardial ischemia in mice, and support recovery from the injuries (7). M2c induced by IL-10, TGF- $\beta$ and glucocorticoids are acquired for the deactivation of macrophages, and participate in anti-inflammation responses, matrix deposition and tissue remodeling (8). The increased expression of the Mer receptor tyrosine kinase on $\mathrm{M} 2 \mathrm{c}$ enables more efficient uptake of apoptotic cells compared with other macrophage subsets in an anti-inflammatory and pro-tumor manner (Fig. 1). M2d induced by IL- $6,8,17,18$, leukemia inhibitory factor and adenosine are characterized by increased expression of IL-10, TGF- $\beta$ inducible nitric oxide synthase (iNOS) and vascular endothelial growth factor (VEGF), and decreased expression of IL-12, TNF- $\alpha$ and IL-1 $\beta$ (9). The increased levels of VEGF, IL-10 and iNOS in M2d endow its abilities of tissue repair and angiogenesis that benefit the metastasis of tumor cells (10) (Fig. 1).

M2-like TAMs are the major component of tumor-infiltrating immune cells in the TME. The predominate presence of M2-like TAMs in the TME is partially responsible for immunosuppression in tumor growth. Individuals with a high M1 to M2 ratio are less susceptible to tumors (11). The ratio of M1-like and M2-like TAMs in the TME is positively associated with the overall survival and prognosis of patients with uveal melanomas (12). By inhibiting the secretion of M1-like TAM-induced factor by epigenetically silencing aberrant DNA methylation, gastric cancer cells evade tumor immune surveillance during the transformation of benign cells into invasive cancer cells (13). The transformation from M2-like to M1-like TAMs under specific conditions results in the recession of lung cancer (14). Therefore, blocking the infiltration of macrophages, eliminating the accumulation of M2-like TAMs, re-polarizing predominant M2-like into M1-like TAMs or epigenetically silencing the secretion of M2-like TAM-induced factors in the TME may be potential candidate mechanisms for TAMs-targeted cancer immunotherapy. The present review summarizes current knowledge regarding the recruitment of macrophages, their polarization into M1-like or M2-like TAMs, and their differential roles in angiogenesis, angiostasis, invasion, metastasis and immune activity in the TME, which may offer valuable insight into how to improve the design of TAMs-targeted cancer immunotherapies. Some of these strategies show promising effects; however, challenges still remain (15).

\section{The recruitment of macrophages into the TME}

In terms of anatomy, macrophages can be divided into tissue-resident and circulating monocytes-derived macrophages. Tissue-resident macrophages are hypothesized to be the first being reprogrammed by tumor cells into pro-tumoral M2-like TAMs. Subsequently, monocyte-derived macrophages are recruited and polarized into M2-like TAMs in the TME, which is critical for the establishment of metastatic and malignant tumors (16). Chemoattractants and their receptors that have been identified to recruit macrophages into the TME include: CCL2/CC receptor (R) $2^{+}$, CCL $2 / \mathrm{CCR}^{+}$, IL-1 $\beta / \mathrm{IL}-1 \mathrm{R}, \mathrm{VEGFA} / \mathrm{VEGFR}$, colony-stimulating factor (CSF) $1 / \mathrm{CSFR}$ and tyrosine-protein kinase receptor (Tie)/Angiogenin 2 (ANG2) (17). For example, CCL2 expressed by tumor cells and macrophages promotes the recruitment of $\mathrm{CCR} 2^{+}$monocytes and $\mathrm{CCR} 5^{+}$granulocytes into the TME, promoting tumor growth and metastasis (18). Among the chemoattractants CCL5, C-X-C motif chemokine ligand (CXCL) 10, CXCL12 and complement Clq, the latter is the most potent attractant promoting M2-like TAMs recruitment (19).

Signaling pathways that function downstream of chemoattractant-receptor pairs for recruiting macrophages into TME include the TGF- $\beta$, PI3K $\gamma$, TLR and mTOR pathways. TGF- $\beta$ mediates the recruitment of macrophages that compete with dendritic cells (DCs), and decreases the antigen-presenting ability of DCs in the adaptive immune system in skin cancer, which result in the transformation of a regressing tumor into a progressing tumor (20). Periostin (POSTN), secreted by ovarian cancer cells, recruits macrophages into the tumor tissue, where macrophages further increase the expression of POSTN in ovarian cancer cells through the production of TGF- $\beta$. In turn, the increased expression of POSTN facilitates the recruitment of macrophages into the TME (21). Activation of the CSF1/CSF1R signaling axis enhances epidermal growth factor (EGF) expression, and promotes the recruitment of macrophages and the migration of epithelial cells in tumor tissues. Conversely, the inhibition of CSF1 receptor signaling abolishes TAM infiltration, enhances the recruitment of $\mathrm{CD}^{+} \mathrm{T}$ cells and reduces the growth of cervical and breast tumors (22).

The tropism of macrophages to hypoxia drives the migration and infiltration of macrophages into the hypoxic tumor compartments (23). This migration is halted by hypoxia-inducible transcription factor (HIF)-1 $\alpha$, when macrophages arrive in tumor compartments, where macrophages are polarized into hypoxic TAMs in order to promote tumor growth and metastasis (23). The pro-tumor function of hypoxic TAMs was confirmed by macrophage-specific genetic deletion of neuropilin (Nrp)-1, a binding partner of hypoxia-induced TAM attractant semaphorin 3A (Sema3A). The deletion of Nrp-1 impedes macrophage entry into hypoxic tumor compartments by blocking the Sema3A/Nrp1 signaling cascade, inhibiting angiogenesis and restoring antitumor activity (24). Hypoxia stimulates the production of VEGF and induces skin carcinogenesis through the recruitment and alternative activation of macrophages. Hypoxia-associated chemoattractant endothelial monocyte-activating polypeptide (EMAP) 2 also stimulates macrophage recruitment under hypoxic conditions (25). In hypoxic melanoma cells, HIF-1 $\alpha$ induces the translocation and secretion of high-mobility group box-1 (HMGB1) that increases IL-10 production and M2-like TAM activation (26). HIF-1 $\alpha$ increases forkhead box protein M1 expression and mediates hypoxia-inducible epithelial-mesenchymal transition (EMT) in prostate cancer (27). In addition, extracellular matrix (ECM) components, integrins, and immunoglobulins in the TME can promote the infiltration of monocytes and macrophages. For example, p110 $\gamma$ activated by tumor-derived chemoattractants, such as receptor tyrosine kinases (RTKs), TLR/IL1Rs or G protein-coupled receptors (GRCRs), selectively promotes the infiltration of myeloid cells into the TME (28). Matrix metalloproteinases (MMPs) can degrade the ECM and regulate signaling pathways that control cell growth, inflammation and angiogenesis, and can even 


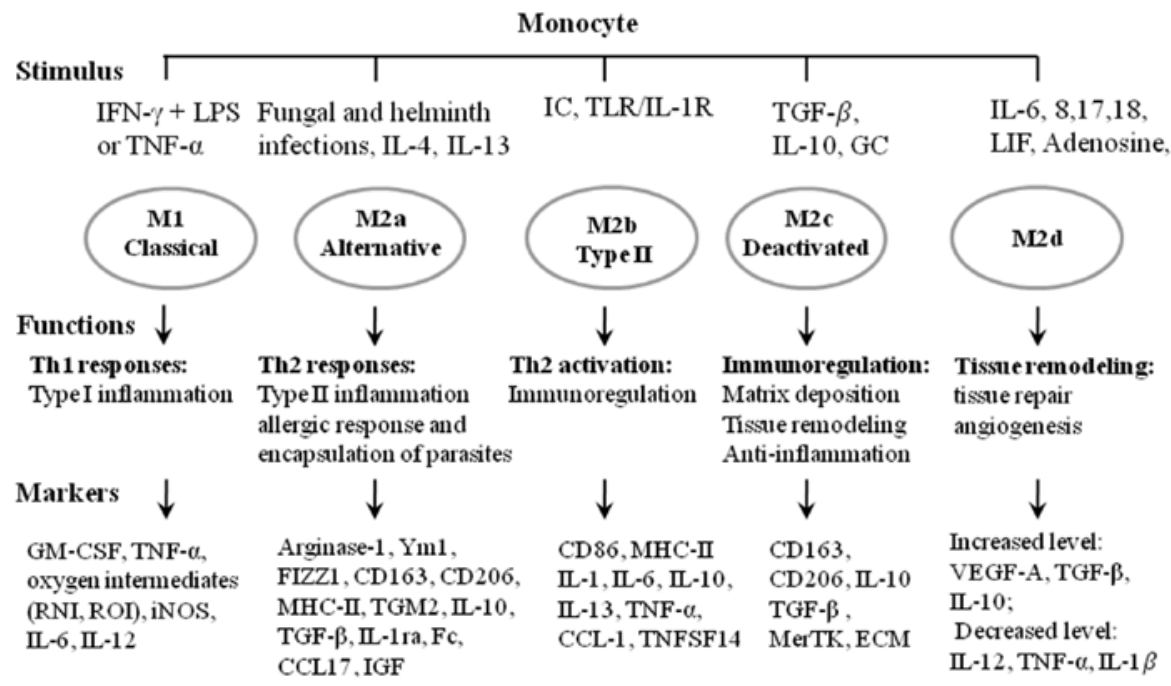

Figure 1. Overview of macrophage activation. Stimuli induce the polarization of different macrophage sub-phenotypes with different functional properties. Markers can be used to identify the distinct sub-phenotypes. IFN, interferon; LPS, lipopolysaccharide; TNF, tumor necrosis factor; IL, interleukin; TLR, toll-like receptor; TGF, tumor growth factor; LIF, leukemia inhibitory factor; GM-CSF, granulocyte macrophage colony-stimulating factor; RNI, reactive nitrogen intermediate; ROI, reactive oxygen intermediate; iNOS, inducible nitric oxide synthase; FIZZ1, found in inflammatory zone protein 1; MHC, major histocompatibility complex; TGM2, transglutaminase 2; IGF, insulin-like growth factor; ECM, extracellular matrix; VEGF, vascular endothelial growth factor; IC, immune complex; TNFSF14, TNF superfamily member 14; GC, glucocorticoid; MerTK, Mer receptor tyrosine kinase.

work in a non-proteolysis manner (29). Table I summarizes the cytokines, chemokines, growth factors, metabolites, integrins, immunoglobulins and selectins that are associated with M2-like TAMs recruitment in the TME.

Apart from the recruitment of macrophages mediated by signaling molecules, the interactions between TAMs and other cells, such as apoptotic and non-apoptotic tumor cells, adipocytes, endothelial cell (ECs) and fibroblasts, also recruit macrophages into the TME (Table I). Through the CCL2/IL-1 $\beta / C X C L 12$ signaling pathway, adipocytes recruit and activate macrophages to promote stromal vascularization and angiogenesis before the formation of a tumor (30). Adipocyte fatty acid-binding protein (AFABP) secreted by TAMs and adipocytes facilitates pro-tumor IL-6/STAT3 signaling through the $\mathrm{NF} \kappa \mathrm{B} /$ microRNA (miR)-29b pathway in TAMs with the $\mathrm{CD} 11 \mathrm{~b}^{+} \mathrm{F} 4 / 80^{+}$major histocompatibility (MHC)II-lymphocyte antigen 6 complex phenotype (31). The number of TAMs settled in the vicinity of cancer-associated fibroblasts (CAFs) is significantly correlated with cancer clinical stage. The interactions between TAMs and CAFs promote the recruitment and activation of each other, contributing to neuroblastoma progression (32). Similarly, increased CXCL1 levels in urothelial cancer enhances the recruitment of TAMs and CAFs, the metastasis of cancer cells, and predicts poor prognosis (33). TAMs produce IL-6 and signal via STAT3 to promote the expansion of human hepatocellular cancer stem cells (CSCs) (34). The secretion of CSC-derived chemoattractants, such as CCL2, CCL5 and VEGF-A, are much higher in glioma tissue than in normal tissue, which facilitates macrophage recruitment and may participate in the architecture of the glioma-initiating cell niche (35).

\section{The polarization of macrophages in the TME}

Macrophages are highly plastic and have dynamic phenotypes and functions. Depending on the induction signals, including hypoxia, malignant cell- or infiltrating $\mathrm{T}$ cell-derived cytokines, chemokines, metabolites and enzymes in the TME, macrophages are polarized into M1-like or M2-like TAMs that can be further categorized by Th1/Th2 lymphocyte polarization during inflammation (36). M1-like TAMs associated with Th1 are induced by interferon (IFN)- $\gamma$, CSF 2 , TNF- $\alpha$, oxygen intermediates released by Th1 immune responses, and possess pro-inflammatory and cytotoxic antitumor abilities (Fig. 2) (37). Increased iNOS and pro-inflammatory factors, such as IL-6, IL-12 and IL-4, in M1-like TAMs are associated with a positive prognosis in patients with non-small cell lung cancer (38). Conversely, M2-like TAMs are induced by anti-inflammatory molecules, such as arginase 1 (ARG1), chitinase 3 like 1 (Ym1), interferon regulatory factor (IRF)4, peroxisome proliferator-activated receptor (PPAR) $\gamma$ or cyclic AMP-responsive element-binding protein (CREB), released by Th2 immune responses. This is accompanied by increased numbers of $\mathrm{CD} 4^{+} \mathrm{T}$ cells and a poor prognosis in patients with breast cancer (39). TGF- $\beta$ and IL10 produced by Th2 lymphocytes promote the Th2 response but inhibit Th1 activity, whilst IFN- $\gamma$ and IL-4 produced by Th1 lymphocytes promote the Th1 response but inhibit Th2 activity (40) (Fig. 2). In addition, pro-inflammatory molecules, such as IFN $\gamma$, TLR4, IL12 and NOS that are secreted by the activation of the STAT1, IRF5, NF- $\kappa \mathrm{B}$ or AP1 signaling pathways, promote the Th1 response and the polarization of M1-like TAMs (40). B-Glucan (a dectin-1 ligand) was also found to promote M1 polarization via the $\mathrm{NF} \kappa \mathrm{B} /$ autophagy pathway (41). The reciprocal regulation between M1-like and M2-like TAMs are implemented by STAT1/STAT6, IRF5/IRF4, NF-кB/PPAR $\gamma$, AP1/CREB, and AP1/PPAR $\gamma$ signaling axes (40), which are essential for the initiation, development, and cessation of tumor inflammation, and may be potential targets for modulating the transformation of M1-like and M2-like TAMs in clinical cancer immunotherapies (Fig. 2). However, the importance 
Table I. Cytokines, chemokines and metabolites identified to be associated with M2-like TAMs recruitment in the TME.

Cytokines Chemokines Metabolites Cells

FGF-2,VEGF, EMAP2, CSF1, PDGF, CCL2, CCL3, CCL5, CCL4, High lactate, low pH, IL-25, TGF- $\beta$, HIF-1 $\alpha$, CSF2, IL-4, IL-6, CCL22, CCL17, CCL18, IL-10, TNF- $\alpha$, NF- $\kappa$ B, EGF, P2Y2, HMGB1, Fizz1, ADM, SEMA3A, TLR-4, MMPs, STAT3 and STAT6, PG, serine protease, COX2, cathepsins B and $\mathrm{S}$, endothelin, oncostatin $\mathrm{M}$, eotaxin, CCL20, CCR5, CX3CL1 succinate, LPC, S1P, , CX3CL5, CX3CL6, CXCL8, accumulation, ribosomal CX3CL8, CX3CL, CX3CR1 CX3CL16, CXCL12
Apoptotic tumor cells, adipocyte, tumor cell, endothelial cell, fibroblasts and cancer stem cells $\mathrm{C} 1 \mathrm{q}$, arginase

TAM, tumor-associated macrophage; TME, tumor microenvironment; FGF, fibroblast growth factor; VEGF, vascular endothelial growth factor; EMAP2 (AIMP1), aminoacyl tRNA synthetase complex interacting multifunctional protein 1; CSF, colony stimulating factor; IL, interleukin; PDGF, platelet derived growth factor; P2Y2, purinergic receptor P2Y2; HMGB1, high-mobility group box-1; TGF, transforming growth factor; HIF, hypoxia inducible factor; TNF, tumor necrosis factor; TLRs, toll-like receptor; CCL, C-C motif chemokine ligand; NF- $\kappa B$, nuclear factor kappa B; FIZZ1, found in inflammatory zone 1; ADM, adrenomedullin; SEMA3A, semaphorin 3A; STAT, signal transducer and activator of transcription; PG, progesterone; COX2, cytochrome $c$ oxidase subunit II; C1q, complement C1q; CXCL, C-X-C motif chemokine ligand; MMPs, matrix metalloproteinase; EGF, epidermal growth factor; LPC, Lysophosphatidylcholine; S1P, Sphingosine 1-phosphate.

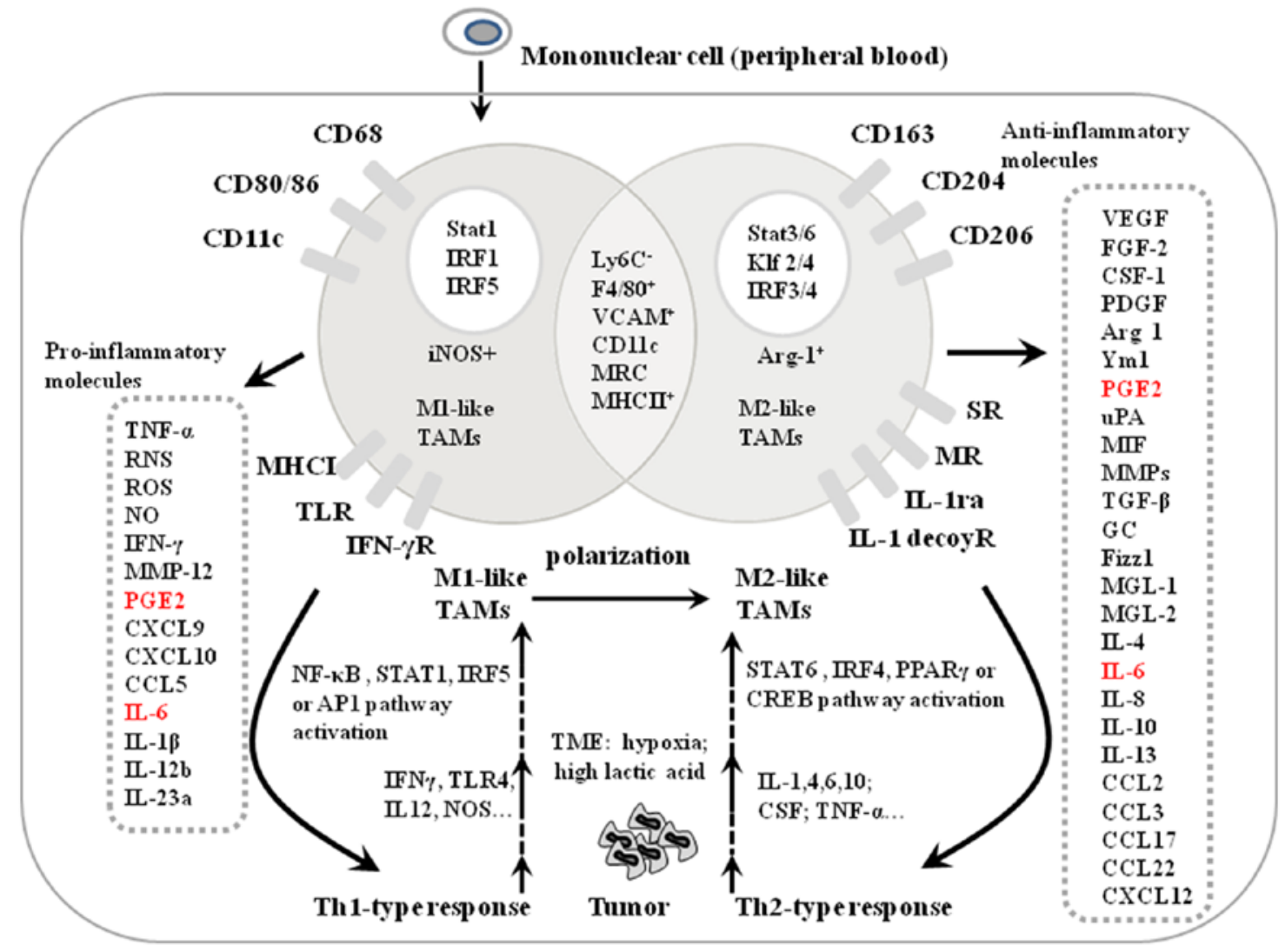

Figure 2. Markers and polarization of M1-like and M2-like TAMs in the tumor microenvironment. Markers to distinguish between M1-like and M2-like TAMs include transcription factors (white circles), pro-inflammatory molecules secreted by M1-like TAMs, anti-inflammatory molecules secreted by M2-like TAMs (grey rectangles) and cell membrane receptors. M1-like and M2-like TAMs share some common characteristics by secreting the same factors, indicated by the overlay region of the two circles. Pro-inflammatory molecules secreted by M1-like TAMs have tumor cytotoxicity inducing the Th1 response (solid line arrows), and anti-inflammatory molecules secreted by M2-like TAMs trigger the Th2 response (solid line arrows). PGE2 and IL-6 secreted by both M1- and M2-like TAMs are indicated by red letters. Molecules secreted by Th1 and Th2 cell responses induce the polarization of M1- and M2-like TAMs, respectively (dotted arrows). TAM, tumor-associated macrophage; TNF, tumor necrosis factor; RNS, reactive nitrogen species; ROS, reactive oxygen species; NO, nitric oxide; MMP, matrix metalloproteinase; PGE2; CXCL, C-X-C motif chemokine ligand; CCL, C-C motif chemokine ligand; IL, interleukin; TLR, toll-like receptor; MHC, major histocompatibility complex; IFN, interferon; IRF, interferon regulatory factor; NOS, nitric oxide synthase; TME, tumor microenvironment; VCAM, vascular cell adhesion molecule 1; MRC, CD200; Klf, Kruppel like factor; SR, secretin receptor; MR, major histocompatibility complex class I-related; CREB, cyclic AMP-responsive element-binding protein; CSF, colony stimulating factor; VEGF, vascular endothelial growth factor; FGF, fibroblast growth factor; PDGF, platelet-derived growth factor; ARG, Arginase; Ym1, chitinase 3 like 1; PGF2, prostaglandin F; uPA, plasminogen activator, urokinase; MIF, macrophage migration inhibitory factor; GC, glucocorticoid; Fizz1, found in inflammatory zone protein 1; MGL, LLGL scribble cell polarity complex component 1 . 
of these signaling axes in re-polarizing M2-like to M1-like TAMs remains to be assessed in TAMs-targeted cancer immunotherapy.

During the transformation of benign cells into invasive cancer cells, the TME is dominated by cytokines and growth factors resulting in the dominance of Th2-like immunosuppression, rather than a Th1-like pro-inflammatory environment (36). This shift results in M1-like TAMs polarizing into the M2-like TAMs, and the preferential accumulation of M2-like TAMs in the TME. These abundant cytokines and growth factors can be derived from tumor cells and non-tumor cells in the TME. For example, $\mathrm{CD} 4^{+} \mathrm{T}$ cell-derived $\mathrm{Th} 2$ cytokines, such as CSF1, IL-4, IL-13 and IL-10, promote the polarization of M1-like into M2-like TAMs in the TME (42) (Fig. 2). In addition, tumor cell-derived microparticles, lactate and miRs, such as miR-21-5p, miR-125 and miR-146, also promote M2-like TAMs polarization in the TME (43). The TME is dominantly populated by M2-like TAMs, but if M1-like TAMs activity is enhanced, the inhibition of local tumor growth is observed. The transformation of M2-like into M1-like TAMs under specific conditions can result in tumor recession Therefore, altering the landscape of M1-like and M1-like TAMs in the TME may have value as a potential TAMs-targeted cancer immunotherapy (11). This alteration could be mediated by blocking macrophage infiltration, selectively killing M2-like TAMs, re-polarizing M2-like to M1-like TAMs or epigenetically silencing the secretion of M2-like TAM-induced molecules in the TME (44).

\section{Markers of M1-like TAMs and M2-like TAMs}

Macrophages are differentiated into either M1-like or M2-like TAMs, which ensures the intraclonal diversity necessary to maintain an efficient immune response in the TME. As key transcription factors for M1 differentiation, STAT1, IRF1 and IRF5 promote the activation of M1-like TAMs by activating the transcription of NO, IFN- $\gamma$, CXCL10 and MMP-12, and the specific receptors of M1-like TAMs, such as CD68, CD80/86 and CD11c (45) (Fig. 2). The transcription factors STAT3/6, Krueppel-like factor $2 / 4$ and IRF3/4 promote the activation of M2-like TAMs and the ARG1-dependent arginine metabolism (45). Meanwhile, M2-like TAMs secret pro-tumor factors, such as VEGF, fibroblast growth factor (FGF)-2, CSF1, and express unique receptors, including scavenger and mannose receptors CD163, CD206 and CD204 (Fig. 2) (9). Antibodies used for TAMs identification include CD80/86, CD68, Fc $\gamma$ RIII, CD14 and HLA-R for M1-like TAMs, and CD163, CD204, CD206 and Tim-3 for M2-like TAMs (Fig. 2) (46). M1-like TAMs with markers of $\mathrm{F} 4 / 80^{+} \mathrm{CD} 11 \mathrm{c}^{+}$mannose receptor C-type 1 (MRC1) low can be separated from M2-like TAMs with markers of $\mathrm{F} 4 / 80^{+} \mathrm{CD} 11 \mathrm{c}^{-} \mathrm{MRC}^{\text {high }}$ by flow cytometric analysis (47).

\section{TAMs functions in angiogenesis and angiostasis}

The proportion of M2-like TAMs is associated with the microvessel density of tumor tissue (12). Quantitative analysis of spatial associations has demonstrated the co-evolution of TAMs and tumor neovessels during cervical cancer invasion (48). The center of the tumor tissue is abundant with disorganized and immature blood vessels, and these central macrophages are associated with the remolding of blood vessels (49). Through secreting pro-angiogenic cytokines and growth factors, such as ornithine, TGF- $\beta$, VEGF, basic fibroblast growth factor (bFGF) and CSF1, M2-like TAMs provide nutrient factors for tumor angiogenesis (50). Several paracrine axes of M2-like TAMs are reported to trigger angiogenesis in the TME, including EGF/VEGFR2, ANG2/Tie2, CCL-18/ERK, Akt/glycogen synthase kinase (GSK)-3 $\beta /$ Snail, CSF1/CSFR1 and sphingosine-1-phosphate receptor 1/NLR family pyrin domain-containing protein 3 (NLRP3)/IL-1 $\beta$ signaling axes (Fig. 3). MMP-9 activity of bone marrow-derived CD45 ${ }^{+}$ myeloid cells containing Tie ${ }^{+}-\mathrm{VEGFR} 1^{+}-\mathrm{CD} 11 \mathrm{~b}^{+}-\mathrm{F} 4 / 80^{+}$ subpopulations is essential and sufficient to initiate angiogenesis by making sequestered VEGF bioavailable for interaction with its receptor VEGFR2 (51). Decreased levels of macrophage-derived VEGF inhibits angiogenesis in solid tumors by attenuating the formation of vessels (52). CCL-18 secreted by TAMs promotes angiogenesis in breast cancer by activating ERK and Akt/GSK-3 $\beta /$ Snail signaling and induces EMT in human umbilical vein endothelial cells (53). Excess blood and lymphatic vessel growth promote tumor progression, while insufficient growth causes tissue ischemia and lymphedema (54). Lymphatic and blood vascular ECs are regulated by two endothelial specific receptor tyrosine kinase systems: VEGF/VEGFR2 And ANG/Tie (54). HIF1 $\alpha$ upregulates VEGF, Tie2 and ANG2 expression to promote angiogenesis (55). TAMs expressing Tie2 (ANG receptor) migrate towards ANG2 expressed by angiogenic vessel cells, which activates ECs and triggers angiogenesis by establishing an autocrine loop in vascular ECs (55). As shown in Fig. 3, activated ECs secrete ANG2 that interacts with the Tie2 receptor expressed by TAMs, mediating cell-to-cell interactions between ECs and TAMs and recruiting Tie-2-expressing cells to the vasculature (56). Decreased TAM counts mediated by inhibiting CSF1 leads to substantial attenuation in tumor angiogenesis. CSF1 upregulates Tie expression on TAMs. Conditional Tie2 gene knockdown in $\mathrm{MRCl}^{+}$Tie2-expressing macrophages decreases tumor angiogenesis (Fig. 3) (56).

In contrast to M2-like TAM activity in angiogenesis, M1-like TAMs possess angiostatic properties by secreting IL-12, IL-18 and MMP-12 (Fig. 3). For example, the Th1 cell-induced secretion of IFN- $\gamma$, IL-12 and IL-18 stimulates the proliferation of M1-like TAMs and the production of angiostatic factors, such as CXCL10 (57). During tumor progression, PPAR- $\gamma$ expression in tumor tissue can switch M1-like TAMs to M2-like TAMs (12). Selectively blocking PPAR- $\gamma$ expression in tumor tissue may be a potential candidate for TAMs-targeted cancer immunotherapy.

\section{TAMs functions in the invasion and metastasis of tumor cells}

Monitoring tumor metastasis using a multiphoton microscopy real-time imaging system indicated that a large number of TAMs are observed at the margin of tumor tissue, with decreasing numbers in the deeper tumor tissues collected from mouse mammary tumor virus (MMTV)-polyomavirus middle T antigen (PyMT) and MMTV-PyMT/c-fms-GFP mice (49). The observations indicate a critical role of TAMs in the trafficking of tumor cells into non-tumor tissue, particularly as 


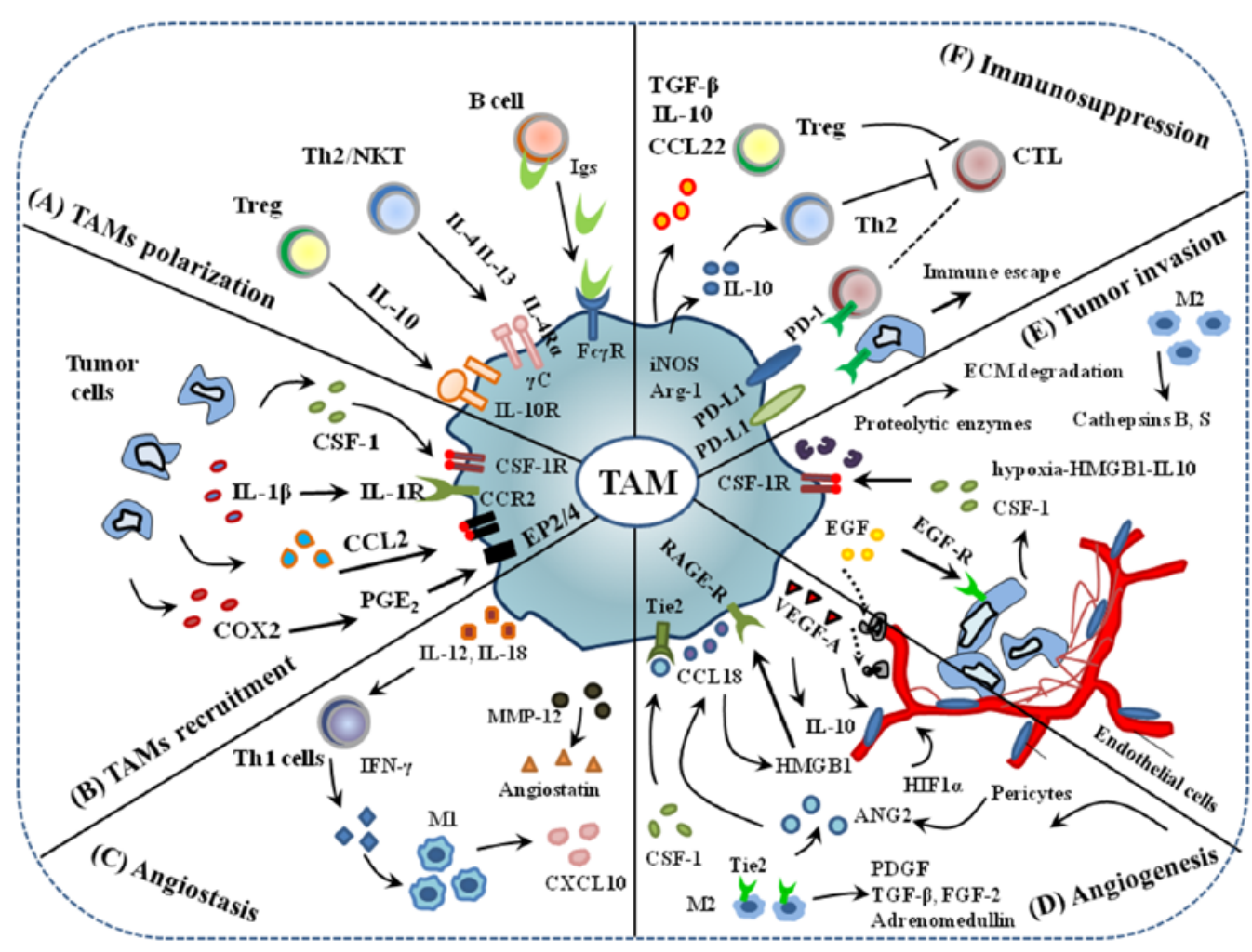

Figure 3. An overview of TAMs in the TME. (A) TAM polarization. (B) Tumor cells secrete signal molecules, such as CSF1 and CCL-2, that interact with their receptors on TAMs to recruit macrophage into the tumor microenvironment. (C) By secreting IL-12, 18 and MMP-12 that enhance the levels of IFN- $\gamma$ and angiostatic factors, such as CXCL10, and stimulate the proliferation of M1 macrophages, TAMs possess angiostasis abilities. (D) TAMs promote angiogenesis through the production of VEGF-A and other angiogenic factors and express the Tie2 receptor that can interact with ECs and pericytes to regulate vascular structure. (E) TAMs secrete proteolytic enzymes, such as MMP and serine protease, to disrupt the basal layer of extracellular matrix to disrupt the organization of vascular ECs into blood vessels. (F) Immunosuppression can occur through soluble or cell surface mediators, for example TAMs express ligands such as CCL-22, IL-10, and PD-L1 that interact with immune infiltrating cells and promote immunosuppression. Immunosuppressive factors TGF- $\beta$, TNF- $\alpha$ and IL-10 released by TAMs activate Tregs that cause immunosuppression in the tumor microenvironment. TAMs, tumor associated macrophages; CSF, colony stimulating factor; IL, interleukin; MMP, matrix metalloproteinase; IFN, interferon; CXCL, C-X-C motif chemokine ligand; VEGF, vascular endothelial growth factor; ECs, endothelial cells; CCL, C-C motif chemokine ligand; PD-L1, programmed cell death-ligand 1; TGF, tumor growth factor; TNF, tumor necrosis factor; B7-H1, B7 homolog 1 or CD274.

the invasion and metastasis of tumor cells are the major cause of cancer-associated mortality rather than primary tumor growth (58).

Several paracrine signaling axes between tumor cells and macrophages mediate the migration of both tumor cells and macrophages, including HMGB1/IL-10, EGF/EGFR, CSF1/CSF1R, TGF-G/SOX9, CCL4/myosin 3A and TLR4/IL-10 (Fig. 3). Tumor hypoxia increases HMGB1 expression in metastatic melanoma, which promotes IL-10 production in M2-like TAMs through the receptor for advanced glycation end-products (26). The paracrine loop between tumor-synthesized CSF1 and macrophage-produced EGF mediates the migration and invasion of tumor cells together with macrophages along collagen fibers, acting as physical pathways towards blood vessels. Inhibition of either CSF1- or EGF-stimulated signaling reduces the migration of both tumor cells and macrophages originating in primary tumor tissues collected from WAP-Cre/CAG-CAT-EGFP/MMTV-PyMT mice (59) (Fig. 3). IL-4-induced Cathepsin protease activity in TAMs promotes pancreatic tumor growth and cell invasion in vitro and in vivo (60). IL-4-expressing $\mathrm{CD}^{+} \mathrm{T}$ lymphocytes indirectly promote invasion and subsequent metastasis of mammary adenocarcinomas by directly regulating the phenotype and effector function of $\mathrm{CD} 11 \mathrm{~b}^{+} \mathrm{Gr} 1-\mathrm{F} 4 / 80^{+} \mathrm{TAMs}$, in turn enhancing metastasis through activating EGFR signaling in malignant mammary epithelial cells (61). In addition, Heregulin B1 and CXCL12 function as tumor metastasis mediators by controlling the EGF/CSF1 paracrine invasion loop (62). Large quantities of Versican produced by Lewis lung cancer cells promote the proliferation of metastatic tumor cells by activating macrophages through the TLR2/TLR6 axis (63). The STAT3/6 signaling pathways synergistically increase Cathepsin secretion from M2-like TAMs, which promote macrophage-mediated pancreatic cancer cell invasion in a Cathepsin-dependent manner (64). In a triple-negative breast cancer mouse model, local and systemic levels of TAM-induced MMP-9, VEGF, Ym1 and Lipocalin-2 mediate metastasis in breast cancer. M2-like TAMs secrete proteases, such as MMPs and serine protease, to disrupt cell-cell junctions, the basal membrane and the organization of vascular ECs into blood vessels, which allows tumor cells to pass through the ECM and facilitate the migration and invasion of tumor cells in numerous types of tumor, including breast and lung cancer (65) (Fig. 3). Hyaluronic acid (HA), a major component of the ECM, is specifically recognized by macrophages expressing the HA receptor CD44 (66). HA-CD44 interactions serve important roles in monocyte adhesion and recruitment, as well as macrophage recruitment to support tumor growth and metastasis (66). 


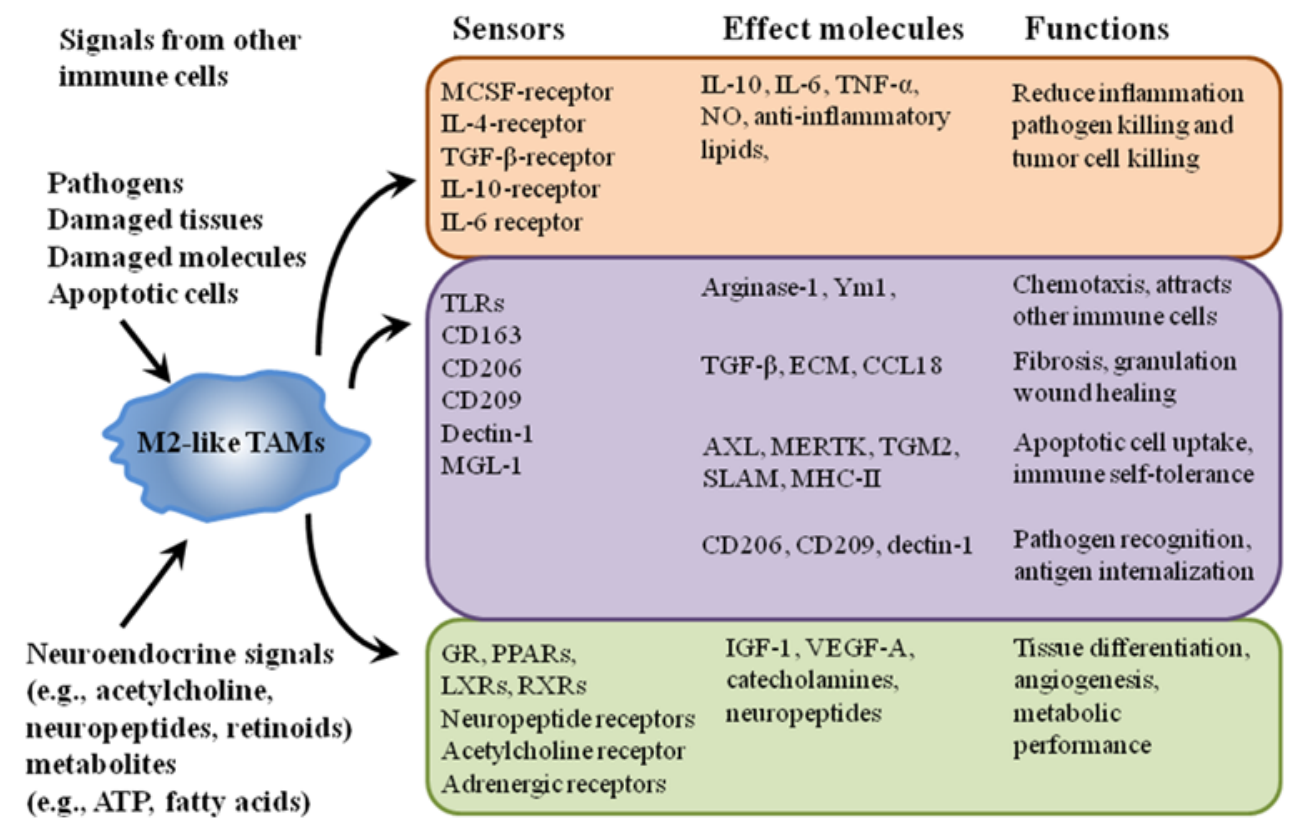

Figure 4. Alternative model depicting sensor and functional effects of the M2-like macrophages. The macrophage phenotype is principally determined by eliciting signals derived from immune cells, pathogens, apoptotic or damaged cells, and a wide range of chemical mediators. These signals act through receptors and signal pathways that elicit a wide range of functional effects. CSF1, colony stimulating factor 1; IL, interleukin; TGF, transforming growth factor; TNF, tumor necrosis factor; Ym1, chitinase 3 like 1; TLR, toll-like receptor; MGL-1, LLGL scribble cell polarity complex component 1; ECM, extracellular matrix; CCL, C-C motif chemokine ligand; AXL, AXL receptor tyrosine kinase; MERTK, MER proto-oncogene tyrosine kinase; TGM2, transglutaminase 2; SLAM, signaling lymphocytic activation molecule; MHC-II, major histocompatibility complex class II; IGF, insulin-like growth factor; VEGF, vascular endothelial growth factor; GR, glutathione reductase; PPAR, peroxisome proliferator activated receptor; LXR, nuclear receptor subfamily 1; RXR, retinoid X receptor.

CXCL1 secreted by M2-like TAMs promotes breast cancer invasion and EMT by activating NF- $\mathrm{KB} / \mathrm{SOX} 4$ signaling (67). In fact, there are several CCLR axes that can enhance the migration of cancer cells by blocking androgen/AR signaling. For example, the CCL5/CCR5 axis inhibits androgen/AR signaling as an upstream mediator in prostate cancer cells (68). While the CCL2/CCR2 axis is negatively regulated by androgen/AR signaling, with the CCL22/CCR4 axis acting as a further downstream mediator, both axes promote prostate cancer cell migration (68). CCL4 promotes prostate carcinogenesis through macrophage androgen/AR signaling. The CCL21/CCR7 axis is activated by TNF- $\alpha$ and induces lymph node metastasis in prostate cancer (68). VEGF-A also stimulate TAMs to produce CXCL1, and elevated CXCL1 in premetastatic liver tissue promotes the recruitment of CXCR2-positive myeloid-derived suppressor cells (MDSCs) to form a premetastatic niche, which ultimately promotes liver metastases (69). Tumor-derived CSF2 induced Bv8 expression in myeloid cells to enhance myelopoiesis and mobilization of MDSCs from the bone marrow (70). The aforementioned data demonstrate that TAMs functions in the invasion and metastasis of tumor cells are complex. A schematic model representing the sensors, effector molecules and the corresponding functions of the M2-like TAMs are illustrated in Fig. 4. Some of these molecules have been defined as M2 markers (such as CD206 and CD163), while others have not (such as CD209), but they all function in the activation of M2-like TAMs (Fig. 4) (71).

\section{TAMs immune effects in the TME}

With high phagocytic capacity, macrophages are the first line of innate immune defense against abnormal cell damage in tissues. By mediating and providing the required costimulatory signaling and cytokine secretion, and identifying and presenting foreign antigens on MHC I and II molecules to $\mathrm{T}$ cells, macrophages also serve a central role in T-cell effective activation of the adaptive immune response (72). M1-like TAMs secrete Th1-inducing NO that can directly kill cancer cells in non-specific manner. In turn, activated Th1 responses further promote the activation of M1-like TAMs, CD8 ${ }^{+}$ $\mathrm{T}$ cells, IgG B cells and IFN- $\gamma$-producing $\mathrm{CD} 4^{+} \mathrm{T}$ cells (73). By releasing pro-inflammatory molecules, such as TNF- $\alpha$, IFN $\gamma$ and ROS/RNS, activating TLRs and decreasing the expression of anti-inflammatory factors, such as ARG1, TGF $\beta$ and IL10, M1-like TAMs promote the inflammatory response and anti-tumor activity in the TME (Fig. 5). These pro-inflammatory cytokines secreted by M1-like TAMs trigger the tumoricidal actions of natural killer (NK) cells, stimulate cytotoxic type Th1 and tumor-specific cytotoxic $\mathrm{T}$ cell responses, and induce the activity of cytotoxic CD8 ${ }^{+}$ T cells (Fig. 5) (73). M1-like TAMs, but not M2-like TAMs, are able to release pro-inflammatory IL-12 that is required in response to the antitumor activities mediated by NK, Th1 and CTL cells (74).

Several chemoattractant, cytokines and enzymes derived from M2-like TAMs can stimulate the activation of induced regulatory $\mathrm{T}$ cells (iTregs) and recruit natural Tregs (nTregs), which exert immunosuppressive effects by directly inhibiting the function of effector $\mathrm{T}$ cells or secreting immunosuppressive factors, such as CCL5 and CCL20 (Fig. 5). For example, M2-like TAM-derived IL-10, TGF- $\beta$, PGE2 and prostanoids inhibit the cytotoxic function of effector $\mathrm{T}$ and NK cells, promote the development of Tregs and activate iTregs and ineffective APCs by upregulating Foxp3 in $\mathrm{CD} 4^{+} \mathrm{T}$ cells (75). 


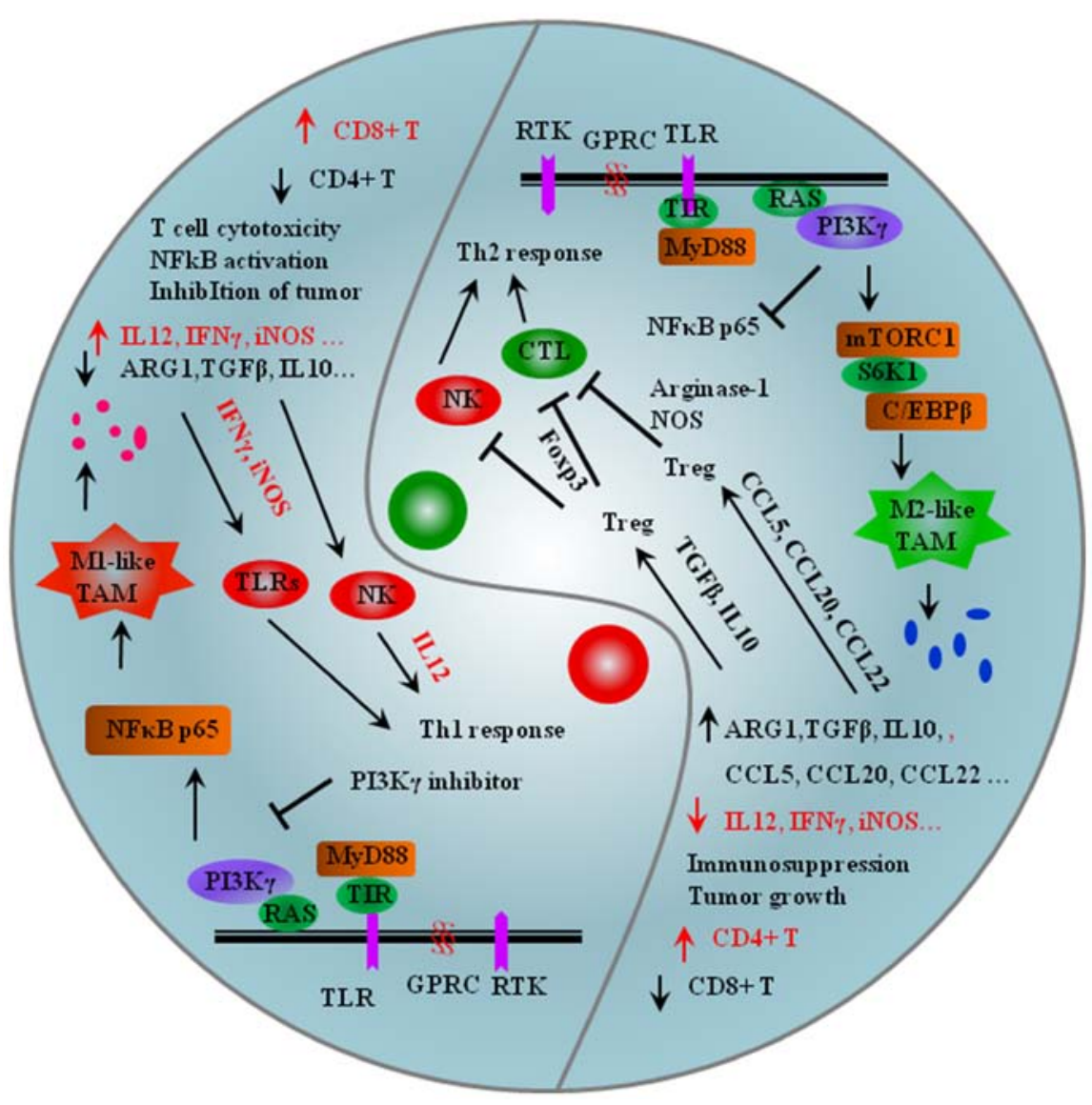

Figure 5. Opposite immune effects of M1-like and M2-like TAMs in the tumor microenvironment. Left: IL12, IFN $\gamma$ and iNOS derived from M1-like TAMs activate NK cells and TLRs that cause Th1 pro-inflammatory response and anti-tumor activity. Inhibition of PI3K $\gamma$ strongly activates the NF- $\mathrm{kB}$ pathway, causing increased expression of proinflammatory factors, including IL12 and IFN $\gamma$. Right: TGF- $\beta$ and IL10 derived from M2-like TAMs activate Tregs by upregulating Foxp3 in CD4+ T cells that cause Th2 anti-inflammatory response and pro-tumor activity. CCL5, CCL20 and CCL22 released by M2-like TAMs activate iTregs, Arginase- 1 and NOS to suppress effector T cells to promote immune suppression in the TME. PI3K $\gamma$ works downstream of many chemoattractant-receptors, such as receptor tyrosine kinases (VEGF-R1 and CSF1R) and G protein-coupled receptors (CCR2 and CXCR4). Inhibition of the NF- $\mathrm{KB}$ pathway activates PI3K $\gamma$, causing increased expression of anti-inflammatory factors, including ARG1, TGF $\beta$ and CCL5. mTORC1, mammalian target of rapamycin complex 1; MyD88, Myeloid differentiation primary response 88 protein; PI3K $\gamma$, phosphoinositide 3-kinase $\gamma$; TIR, toll/interleukin receptor domain; TLR/ILR, Toll-like receptor/interleukin receptor; ARG, Arginase; TGF $\beta$, transforming growth factor $\beta$; CCL, C-C motif chemokine ligand; IL, interleukin; IFN $\gamma$, interferon $\gamma$; iNOS, inducible nitric oxide synthase; GPCR, G protein-coupled receptor; RTK, receptor tyrosine kinase; C/EBP $\beta$, enhancer-binding proteins; RAS, KRAS proto-oncogene, GTPase.

In addition, CCL5, CCL20 and CCL22 released by M2-like TAMs recruit and activate iTregs to suppress the function of effector $\mathrm{T}$ cells, resulting in immune suppression in the TME (Fig. 5). M2-like TAMs secrete CCL22 in human ovarian cancer, mediating Treg trafficking to tumor tissue through the CCL22/CCR4 axis (76). M2-like TAMs secreted CCL20, which recruits $\mathrm{CCR}^{+}$nTregs to promote immunosuppression in the TME (55). M2-like TAMs suppress T cell proliferation in part by expressing ARG1 that catabolizes arginine necessary for $\mathrm{T}$ cell activation and proliferation; decreased arginine levels results in impaired effector $\mathrm{T}$ cell function in the TME (77). Small extracellular vesicles containing ARG1 suppress $\mathrm{CD} 4^{+}$and $\mathrm{CD} 8^{+} \mathrm{T}$ cell proliferation in vitro and in vivo in mouse models of ovarian carcinomas (78). Tumor cells use extracellular vesicles to transport the metabolic checkpoint molecule ARG1 over long distances to immune cells to weaken antitumor immune responses (78).

PI3K $\gamma$ functions downstream of several chemoattractant receptors, such as RTKs (including VEGF-R1 and CSF1R) and GPCR (including CCR2 and CXCR4) (Fig. 5). The inhibition of PI3K $\gamma$ activates the NF- $\mathrm{KB}$ pathway, increases the levels of proinflammatory cytokines, including $\mathrm{TNF} \alpha$, IL-12, NOS2 and MHCII on APCs (including macrophages and DCs), and inhibits the expression of immunosuppressive factors, such as IL-10, TGF $\beta$, ARG1 and CCL2 (79). Chemoattractants such as SDF-1a, VEGFa and IL-1b activate RTKs, GPCRs and TLR/ILR signaling molecules that initiate tumor inflammation by activating the PI3K isoform p110 $\gamma$ in $\mathrm{Grl}^{+} \mathrm{CD} 11 \mathrm{~b}^{+}$myeloid cells (28). M2-like TAMs produce anti-inflammatory immunosuppression and pro-tumor activity by releasing growth-promoting molecules like ornithine, which promotes Th2-type cytotoxic responses, increases the levels of anti-inflammatory cytokines, such as IL-4, IL-10, IL-13 and IL-10, decreases levels of pro-inflammatory factors, including IL12, IFN $\gamma$ and iNOS, and induces ineffective antigen presentation (Fig. 5) (79).

\section{Potential strategies for TAMs-targeted cancer immunotherapy}

The predominate presence of M2-like TAMs in the TME is partially responsible for tumor immune evasion and 
Table II. Strategies for TAM-targeted antitumor therapy.

A, Blocking TAMs infiltration to the TME

\begin{tabular}{llll}
\hline First author, year $\quad$ Potential agents & Mechanism of action
\end{tabular}

Pathria et al, 2019

PF-04136309, MLN1202, CCX872-B CCR-2 inhibitors targeting CCL-2/CCR-2 axis and BMS-813160

B, Depleting M2-like TAMs in the TME

\begin{tabular}{lll}
\hline First author, year & \multicolumn{1}{c}{ Potential agents } & \multicolumn{1}{c}{ Mechanism of action } \\
\hline $\begin{array}{l}\text { Lee } \text { et al, 2019 } \\
\text { Opperman } \text { et al, 2019 }\end{array}$ & $\begin{array}{l}\text { The hybrid peptide of MEL-dKLA } \\
\text { Liposomes with encapsulation of } \\
\text { clodronate }\end{array}$ & $\begin{array}{l}\text { Inducing CD206+ M2-like TAMs apoptosis } \\
\text { Decreases levels of macrophage-derived } \\
\text { insulin-like growth factor 1 }\end{array}$ \\
Zhang et al, 2019 & $\begin{array}{l}\text { Nanocarriers with a nanobody specific } \\
\text { for CD206 }\end{array}$ & $\begin{array}{l}\text { Anti-CD206 nanobodies inhibit angiogenesis } \\
\text { Zhang } \text { et al, 2019 }\end{array}$ \\
In vitro-transcribed mRNA & Switching M1-like reprogramming
\end{tabular}

C, Reprogramming TAMs from M2-like to M1-like TAMs

\begin{tabular}{|c|c|c|c|}
\hline First author, year & Potential agents & Mechanism of action & (Refs.) \\
\hline Wanderley et al, 2018 & Paclitaxel (Taxol) & TLR4-dependent manner & $(85)$ \\
\hline Andersen et al, 2019 & $\begin{array}{l}\text { CD163-targeted corosolic } \\
\text { acid-containing liposomes }\end{array}$ & Specific inhibition of STAT3 & $(84)$ \\
\hline Tan et al, 2015 & Baicalin & Autophagy-associated activation of RelB/p52 & $(87)$ \\
\hline Locatelli et al, 2019 & RP6530 & PI3K $\delta / \gamma$-dependent pathway & $(86)$ \\
\hline Buhtoiarov et al, 2011 & Cyclophosphamide & $\begin{array}{l}\text { Up-regulating the levels of the M1-associated } \\
\text { molecules (CD40, CD80, CD86, MHC class II, } \\
\text { IFN- } \gamma, \text { TNF- } \alpha, \text { IL-12) and down-regulating the } \\
\text { levels of the M2-associated molecules (IL-4R } \alpha \text {, } \\
\text { B7-H1, IL-4, IL-10). }\end{array}$ & (94) \\
\hline Di Caro et al, 2016 & Gemcitabine & $\begin{array}{l}\text { Improving the expression of the M1 markers } \\
\text { HLA-DR, CD } 40, \text { CCR } 7 \text {, decreasing the } \\
\text { expression of M } 2 \text { markers CD163 and CD206 }\end{array}$ & $(95)$ \\
\hline
\end{tabular}

D, TAM-mediated delivery of therapeutic systems

\begin{tabular}{|c|c|c|c|}
\hline First author, year & Potential agents & Mechanism of action & (Refs.) \\
\hline Choi et al, 2012 & $\begin{array}{l}\text { Liposomal-Dox delivered by } \\
\text { macrophages }\end{array}$ & & (91) \\
\hline
\end{tabular}

chemoresistance, and the potential of TAM-targeted tumor immunotherapies has received considerable interest. The current strategies being explored for such cancer treatment include (Table II): i) blocking the infiltration of macrophages into the TME (15); ii) depleting/killing dominating M2-like
TAMs in the TME; iii) reprogramming M2-like TAMs into the M1-like phenotype in the TME (80); and iv) TAM-mediated delivery of therapeutics (81).

Blocking the signaling axes of chemoattractants and their receptors (such as CCL2/CCR2 ${ }^{+}$, CCL2/CCR5 ${ }^{+}$, IL-1 $\beta / I L-1 R$, 
Table III. Potential agents to target the reprogramming TAMs from M2-like to M1-like TAMs in cancer treatment.

\begin{tabular}{|c|c|c|c|}
\hline Agents & Applications & Effects on TAMs & Mechanism of action \\
\hline Paclitaxel (Taxol) & $\begin{array}{l}\text { In vitro and in vivo models of } \\
\text { breast and melanoma tumors }\end{array}$ & $\begin{array}{l}\text { Altered the signature of TAMs } \\
\text { from M2-like to M1-like TAMs }\end{array}$ & TLR4-dependent manner (85) \\
\hline $\begin{array}{l}\text { CD163-targeted corosolic } \\
\text { acid-containing liposomes }\end{array}$ & Monocytes and macrophages & $\begin{array}{l}\text { M1-like reprogramming at the } \\
\text { mRNA level }\end{array}$ & Specific inhibition of STAT384 \\
\hline RP6530 & $\begin{array}{l}\text { Hodgkin lymphoma in vitro } \\
\text { and in vivo }\end{array}$ & Switching M1-like reprogramming & $\begin{array}{l}\mathrm{PI} 3 \mathrm{~K} \delta / \gamma \text {-dependent } \\
\text { pathway }(86)\end{array}$ \\
\hline $\begin{array}{l}\text { The hybrid peptide of } \\
\text { MEL-dKLA }\end{array}$ & $\begin{array}{l}\text { In vitro and in mouse models } \\
\text { of lung carcinoma }\end{array}$ & $\begin{array}{l}\text { Induced apoptosis in CD206+ } \\
\text { M2-like TAMs }\end{array}$ & $\begin{array}{l}\text { Induces mitochondrial death } \\
\text { after cell membrane } \\
\text { penetration (68) }\end{array}$ \\
\hline Baicalin & $\begin{array}{l}\text { In vitro and in vivo } \\
\text { hepatocellular carcinoma } \\
\text { mouse model }\end{array}$ & $\begin{array}{l}\text { Initiating TAM reprogramming } \\
\text { to an M1-like TAM }\end{array}$ & $\begin{array}{l}\text { Autophagy-associated } \\
\text { activation of RelB/p52 (87) }\end{array}$ \\
\hline Cyclophosphamide & $\begin{array}{l}\text { Multiple myeloma, leukemia, } \\
\text { breast cancer, neuroblastoma, } \\
\text { lymphoma, ovarian cancer, } \\
\text { retinoblastoma }\end{array}$ & $\begin{array}{l}\text { Altered the signature of TAMs } \\
\text { from M2-like to M1-like TAMs } \\
\text { in a manner }\end{array}$ & $\begin{array}{l}\text { Enhances pro-inflammatory } \\
\text { IL- } 6 \text { and IL-12, and decreases } \\
\text { anti-inflammatory IL-10 and } \\
\text { TGF- } \beta \text { (94) }\end{array}$ \\
\hline Gemcitabine & & $\begin{array}{l}\text { Re-education of macrophages } \\
\text { to M1-like TAMs by upregulating } \\
\text { the levels of the M1 markers } \\
\text { HLA-DR, CD } 40, \text { CCR7, } \\
\text { downregulating the levels of M2 } \\
\text { markers CD163 and CD206 }\end{array}$ & $\begin{array}{l}\text { Activation of the } \\
\text { pro-inflammatory M1-like } \\
\text { TAMs (95) }\end{array}$ \\
\hline $\begin{array}{l}\text { Nanocarrier encoding } \\
\text { M1-polarizing } \\
\text { transcription factors }\end{array}$ & & $\begin{array}{l}\text { Reprogramming M2-like TAMs } \\
\text { to M1-like TAMs }\end{array}$ & $\begin{array}{l}\text { Induces anti-tumor immunity } \\
\text { and tumor regression (93) }\end{array}$ \\
\hline
\end{tabular}

TAM, tumor-associated macrophage; TLR, Toll-like receptor; STAT, signal transducer and activator of transcription; CCL, C-C motif chemokine ligand; CCR, C-C motif chemokine Receptor; MEL, melittin; dKLA, pro-apoptotic peptide d; PI3K $\gamma$, phosphoinositide 3-kinase $\gamma$; IL, interleukin; HLA-DR, human leucocyte antigens-DR isotype; TNF, tumor necrosis factor; B7-H1, B7 homolog 1 or CD274; IFN, interferon; MHC, major histocompatibility complex; RELB proto-oncogene, NF- $\mathrm{BB}$ subunit; TGF, transforming growth factor.

VEGFA/VEGFR, CSF1/CSFR and Tie/ANG2) may be potential candidates for targeting macrophage-recruitment therapy. For example, clinical trials with several CCR-2 inhibitors, such as PF-04136309 and MLN1202, are currently ongoing for the treatment of solid tumors, including pancreatic ductal adenocarcinoma and colorectal cancer (79) (Table III). Combination of therapy blocking CCL-2 or CCR-2 signaling with chemo-, radio- or immunotherapy improves antitumor effects by decreasing the infiltration of myeloid cells in preclinical mouse models (82). In addition to therapy blocking macrophage recruitment, selective elimination of the dominating M2-like TAMs in the TME can inhibit tumor growth and restore local immune surveillance. For example, a hybrid peptide of MEL-dKLA selectively triggered M2-like TAM apoptosis without affecting other leukocytes, such as $\mathrm{T}$ cells and DCs, and increased the M1/M2 ratio, which reduced tumor growth rates, tumor weights and angiogenesis in a lung cancer mouse model (83) (Table III).

Different studies have shown that genetic or epigenetic reprogramming of M2-like TAMs into M1-like TAMs in the TME has promising effects. Specific STAT3 inhibition in human monocytes and macrophages by CD163-targeted corosolic acid-containing liposomes promotes M1-like TAMs reprogramming, inhibits STAT3-regulated IL-10 expression and increases pro-inflammatory TNF $\alpha$ levels (84). Paclitaxel alters the signature of TAMs in the TME from a M2-like pro-tumor profile (CD206, RELM $\alpha$, MMP9 and ARG1) to a M1-like antitumor profile (IL12, iNOS and IL6), inducing tumor regression by reprogramming in a TLR4-dependent manner in mouse models of breast and melanoma tumors (85) (Table III). RP6530 re-polarizes M2-like TAMs into M1-like TAMs to inhibit the growth of tumor vasculature, leading to tumor regression via the $\mathrm{PI} 3 \mathrm{~K} \delta / \gamma$-dependent pathway (86). Oral administration of baicalin mediates the re-polarization of M2-like into M1-like TAMs in the TME and the inhibition of hepatocellular carcinoma in an orthotopic mouse model by autophagy-induced RelB/p52 activation (87). The combination of PMX-53 (a C5aR1 peptide antagonist) and paclitaxel synergistically inhibits tumor growth by re-polarizing M2-like towards the M1-like TAM phenotype, inhibiting angiogenesis and recruiting cytotoxic T lymphocytes (88). TMP195 re-polarizes M2-like into M1-like TAMs and synergizes with 
PD-1 antibody to reduce tumor burden and metastasis in an autochthonous mouse model of breast cancer (89). In addition, macrophages have great potential in cancer drug delivery because they can sense chemotactic cues and migrate to tumors with high efficiency (90). For example, liposomal-doxorubicin delivered by macrophages exhibited higher therapeutic efficacy than doxorubicin delivered by liposome or doxorubicin alone in both subcutaneous and metastasis xenograft lung tumor models (91) (Tables II and III). Therapy with Dox-laden nanocapsules leads to efficient tumor growth suppression, while causing little systemic toxicity in U87MG tumor bearing nude mice (90).

\section{Conclusion}

As summarized in the present review, the preferential accumulation of M2-like TAMs is a major contributor to the establishment of metastatic and malignant tumors. TAM-targeted cancer immunotherapies are now being explored and developed, including: i) Blocking macrophage recruitment; ii) M2-like TAM-targeted depletion in the TEM; iii) M2-like TAM-targeted reprogramming therapy in the TEM; and iv) macrophage-mediated drug delivery systems. However, there are a number of unsolved challenges, such as rapid clearance from the blood circulation, inefficient targeting and cytotoxicity issues, that will limit the application of TAM-targeted therapy in the clinic. Additionally, increasing M1-like TAMs through the re-polarization of M2-like TAMs into M1-like TAMs may induce the infiltration of T lymphocytes into tumors and increase their ability to kill tumor cells, while overzealous M1-like TAMs contributing to chronic inflammation may lead to atherosclerosis and other chronic inflammatory conditions (11). New technologies, such as single cell sequencing, and digitalization and visual spatial analysis models, may help to resolve some of these problems.

\section{Acknowledgements}

Not applicable.

\section{Funding}

The present study was supported by grants from the National Nature Science Foundation of China (grant no. 31160233), the Undergraduate Innovation Program at Nanchang University (grant no. 20190402294) and the Science and Technology Foundation of Jiangxi Province (grant no. 20142BAB204013).

\section{Availability of data and materials}

Not applicable.

\section{Authors' contributions}

$\mathrm{MY}$ and $\mathrm{KZ}$ were responsible for the writing of the manuscript. JZ, XP and YZ prepared Figures 1-3. JW and XC prepared Figure 4 and Table I. TC modified the writing of the manuscript and the figures. All authors participated in the whole process of writing and modifying the manuscript, and read and approved the final manuscript.

\section{Ethics approval and consent to participate}

Not applicable.

\section{Patient consent to participate}

Not applicable.

\section{Competing interests}

The authors declare that they have no competing interests.

\section{References}

1. Zent CS and Elliott MR: Maxed out macs: Physiologic cell clearance as a function of macrophage phagocytic capacity. FEBS J 284: 1021-1039, 2017.

2. Zhang Q, L Y., Bian H, Guo L and Zhu H: Activation of the $\alpha 7$ nicotinic receptor promotes lipopolysaccharide-induced conversion of M1 microglia to M2. Am J Transl Res 9: 971-985, 2017.

3. Yao Y, Xu XH and Jin L: Macrophage Polarization in physiological and pathological pregnancy. Front Immunol 10: 792, 2019.

4. Gordon S: Alternative activation of macrophages. Nat Rev Immunol 3: 23-35, 2003.

5. Gensel JC and Zhang B: Macrophage activation and its role in repair and pathology after spinal cord injury. Brain Res 1619: 1-11, 2015.

6. Lefèvre L, Lugo-Villarino G, Meunier E, Valentin A, Olagnier D, Authier H, Duval C, Dardenne C, Bernad J, Lemesre JL, et al: The C-type lectin receptors dectin-1, MR, and SIGNR3 contribute both positively and negatively to the macrophage response to Leishmania infantum. Immunity 38: 1038-1049, 2013.

7. Wang LX, Zhang SX, Wu HJ, Rong XL and Guo J: M2b macrophage polarization and its roles in diseases. J Leukoc Biol 106: 345-358, 2019.

8. Wang Y, Smith W, Hao D, He B and Kong L: M1 and M2 macrophage polarization and potentially therapeutic naturally occurring compounds. Int Immunopharmacol 70: 459-466, 2019.

9. Yang L and Zhang Y: Tumor-associated macrophages: From basic research to clinical application. J Hematol Oncol 10: 58, 2017.

10. Ferrante CJ, Pinhal-Enfield G, Elson G, Cronstein BN, Hasko G, Outram S and Leibovich SJ: The adenosine-dependent angiogenic switch of macrophages to an M2-like phenotype is independent of interleukin- 4 receptor alpha (IL-4R $\alpha$ ) signaling. Inflammation 36: 921-931, 2013.

11. Mills CD, Lenz LL and Harris RA: A breakthrough: Macrophage-directed cancer immunotherapy. Cancer Res 76: 513-516, 2016.

12. Herwig MC, Bergstrom C, Wells JR, Höller $\mathrm{T}$ and Grossniklaus HE: M2/M1 ratio of tumor associated macrophages and PPAR-gamma expression in uveal melanomas with class 1 and class 2 molecular profiles. Exp Eye Res 107: 52-58, 2013.

13. Wang HC, Chen CW, Yang CL, Tsai IM, Hou YC, Chen CJ and Shan YS: Tumor-associated macrophages promote epigenetic silencing of gelsolin through DNA methyltransferase 1 in gastric cancer cells. Cancer Immunol Res 5: 885-897, 2017.

14. Sarode P, Zheng X, Giotopoulou GA, Weigert A, Kuenne C, Günther S, Friedrich A, Gattenlöhner S, Stiewe T, Brüne B, et al: Reprogramming of tumor-associated macrophages by targeting $\beta$-catenin/FOSL2/ARID5A signaling: A potential treatment of lung cancer. Sci Adv 6: eaaz6105, 2020.

15. Li X, Liu R, Su X, Pan Y, Han X, Shao C and Shi Y: Harnessing tumor-associated macrophages as aids for cancer immunotherapy. Mol Cancer 18: 177, 2019.

16. Larionova I, Cherdyntseva N, Liu T, Patysheva M, Rakina M and Kzhyshkowska J: Interaction of tumor-associated macrophages and cancer chemotherapy. Oncoimmunology 8: 1596004, 2019.

17. Lee HW, Choi HJ, Ha SJ, Lee KT and Kwon YG: Recruitment of monocytes/macrophages in different tumor microenvironments. Biochim Biophys Acta 1835: 170-179, 2013.

18. Fantuzzi L, Tagliamonte M, Gauzzi MC and Lopalco L: Dual CCR5/CCR2 targeting: Opportunities for the cure of complex disorders. Cell Mol Life Sci 76: 4869-4886, 2019. 
19. Vogel DY, Heijnen PD, Breur M, de Vries HE, Tool AT, Amor S and Dijkstra CD: Macrophages migrate in an activation-dependent manner to chemokines involved in neuroinflammation. J Neuroinflammation 11: 23, 2014

20. Byrne SN, Knox MC and Halliday GM: TGFbeta is responsible for skin tumour infiltration by macrophages enabling the tumours to escape immune destruction. Immunol Cell Biol 86 92-97, 2008

21. Tang M, Liu B, Bu X and Zhao P: Cross-talk between ovarian cancer cells and macrophages through periostin promotes macrophage recruitment. Cancer Sci 109: 1309-1318, 2018.

22. Ruffell B, Affara NI and Coussens LM: Differential macrophage programming in the tumor microenvironment. Trends Immunol 33: 119-126, 2012.

23. Henze AT and Mazzone M: The impact of hypoxia on tumorassociated macrophages. J Clin Invest 26: 3672-3679, 2016.

24. Casazza A, Laoui D, Wenes M, Rizzolio S, Bassani N, Mambretti M, Deschoemaeker S, Van Ginderachter JA, Tamagnone L and Mazzone M: Impeding macrophage entry into hypoxic tumor areas by Sema3A/Nrp1 signaling blockade inhibits angiogenesis and restores antitumor immunity. Cancer Cell 24: 695-709, 2013.

25. Clarijs R, Schalkwijk L, Ruiter DJ and de Waal RM: EMAP-II expression is associated with macrophage accumulation in primary uveal melanoma. Invest Ophthalmol Vis Sci 44: 1801-1816, 2003

26. Huber R, Meier B, Otsuka A, Fenini G, Satoh T, Gehrke S Widmer D, Levesque MP, Mangana J, Kerl K, et al: Tumour hypoxia promotes melanoma growth and metastasis via high mobility group box-1 and M2-like macrophages. Sci Rep 6: 29914, 2016

27. Tang C, Liu T, Wang K, Wang X, Xu S, He D and Zeng J: Transcriptional regulation of FoxM1 by HIF-1 $\alpha$ mediates hypoxia-induced EMT in prostate cancer. Oncol Rep 42: $1307-1318,2019$

28. Schmid MC, Avraamides CJ, Dippold HC, Franco I, Foubert P, Ellies LG, Acevedo LM, Manglicmot JR, Song X, Wrasidlo W, et al: Receptor tyrosine kinases and TLR/IL1Rs unexpectedly activate myeloid cell PI $3 \mathrm{k} \gamma$, a single convergent point promoting tumor inflammation and progression. Cancer Cell 19: 715-727, 2011.

29. Kessenbrock K, Plaks V and Werb Z: Matrix metalloproteinases: Regulators of the tumor microenvironment. Cell 141: 52-67, 2010

30. Arendt LM, McCready J, Keller PJ, Baker DD, Naber SP Seewaldt V and Kuperwasser C: Obesity promotes breast cancer by CCL2-mediated macrophage recruitment and angiogenesis. Cancer Res 73: 6080-6093, 2013.

31. Hao J, Yan F, Zhang Y, Triplett A, Zhang Y, Schultz DA, Sun Y, Zeng J, Silverstein KAT, Zheng Q, et al: Expression of adipocyte/macrophage fatty acid binding protein in tumor associated macrophages promotes breast cancer progression. Cancer Res 78: 2343-2355, 2018.

32. Komohara Y and Takeya M: CAFs and TAMs: Maestros of the tumour microenvironment. J Pathol 241: 313-315, 2017.

33. Miyake M, Hori S, Morizawa Y, Tatsumi Y, Nakai Y, Anai S, Torimoto K, Aoki K, Tanaka N, Shimada K, et al: CXCL1-mediated interaction of cancer cells with tumor-associated macrophages and cancer-associated fibroblasts promotes tumor progression in human bladder cancer. Neoplasia 18: 636-646, 2016.

34. Wan S, Zhao E, Kryczek I, Vatan L, Sadovskaya A, Ludema G Simeone DM, Zou W and Welling TH: Tumor-associated macrophages produce interleukin 6 and signal via STAT3 to promote expansion of human hepatocellular carcinoma stem cells. Gastroenterology 147: 1393-1404, 2014.

35. Yi L, Xiao H, Xu M, Ye X, Hu J, Li F, Li M, Luo C, Yu S, Bian X and Feng H: Glioma-initiating cells: A predominant role in microglia/macrophages tropism to glioma. J Neuroimmunol 232: 75-82, 2011.

36. Biswas SK and Mantovani A: Macrophage plasticity and interaction with lymphocyte subsets: Cancer as a paradigm. Na Immunol 11: 889-896, 2010.

37. Murray PJ: Macrophage polarization. Annu Rev Physiol 79: 541-566, 2017.

38. Chen JJ, Yao PL, Yuan A, Hong TM, Shun CT, Kuo ML, Lee YC and Yang PC: Up-regulation of tumor interleukin-8 expression by infiltrating macrophages: Its correlation with tumor angiogenesis and patient survival in non-small cell lung cancer. Clin Cancer Res 9: 729-737, 2003

39. Noy R and Pollard JW: Tumor-associated macrophages: From mechanisms to therapy. Immunity 41: 49-61, 2014.
40. Liu YC, Zou XB, Chai YF and Yao YM: Macrophage polarization in inflammatory diseases. Int J Biol Sci 10: 520-529, 2014.

41. Li X, Luo H, Ye Y, Chen X, Zou Y, Duan J and Xiang D: $\beta$-glucan, a dectin-1 ligand, promotes macrophage M1 polarization via NF- $\mathrm{B}$ /autophagy pathway. Int J Oncol 54: 271-282, 2019.

42. Su S, Liu Q, Chen J, Chen J, Chen F, He C, Huang D, Wu W, Lin L, Huang W, et al: A positive feedback loop between mesenchymal-like cancer cells and macrophages is essential to breast cancer metastasis. Cancer Cell 25: 605-620, 2014.

43. Pan Z, Tian Y, Niu G and Cao C: Role of microRNAs in remodeling the tumor microenvironment. Int J Oncol 56: 407-416, 2020.

44. Peng D, Kryczek I, Nagarsheth N, Zhao L, Wei S, Wang W, Sun Y, Zhao E, Vatan L, Szeliga W, et al: Epigenetic silencing of TH1-type chemokines shapes tumour immunity and immunotherapy. Nature 527: 249-253, 2015.

45. Lawrence T and Natoli G: Transcriptional regulation of macrophage polarization: Enabling diversity with identity. Nat Rev Immunol 11: 750-761, 2011.

46. Heusinkveld $\mathrm{M}$ and van der Burg SH: Identification and manipulation of tumor associated macrophages in human cancers. J Transl Med 9: 216, 2011.

47. Rolny C, Mazzone M, Tugues S, Laoui D, Johansson I, Coulon C, Squadrito ML, Segura I, Li X, Knevels E, et al: HRG inhibits tumor growth and metastasis by inducing macrophage polarization and vessel normalization through downregulation of PIGF. Cancer Cell 19: 31-44, 2011.

48. Jiang S, Yang Y, Fang M, Li X, Yuan X and Yuan J: Co-evolution of tumor-associated macrophages and tumor neo-vessels during cervical cancer invasion. Oncol Lett 12: 2625-2631, 2016.

49. Wyckoff JB, Wang Y, Lin EY, Li JF, Goswami S, Stanley ER, Segall JE, Pollard JW and Condeelis J: Direct visualization of macrophage-assisted tumor cell intravasation in mammary tumors. Cancer Res 67: 2649-2656, 2007.

50. Caux C, Ramos RN, Prendergast GC, Bendriss-Vermare N and Ménétrier-Caux C: A Milestone review on how macrophages affect tumor growth. Cancer Res 76: 6439-6442, 2016.

51. Du R, Lu KV, Petritsch C, Liu P, Ganss R, Passegué E, Song H, Vandenberg S, Johnson RS, Werb Z and Bergers G: HIF1alpha induces the recruitment of bone marrow-derived vascular modulatory cells to regulate tumor angiogenesis and invasion. Cancer Cell 13: 206-220, 2008

52. Stockmann C, Doedens A, Weidemann A, Zhang N, Takeda N, Greenberg JI, Cheresh DA and Johnson RS: Deletion of vascular endothelial growth factor in myeloid cells accelerates tumorigenesis. Nature 456: 814-818, 2008.

53. Lin L, Chen YS, Yao YD, Chen JQ, Chen JN, Huang SY, Zeng YJ, Yao HR, Zeng SH, Fu YS and Song EW: CCL18 from tumor-associated macrophages promotes angiogenesis in breast cancer. Oncotarget 6: 34758-34773, 2015 .

54. Saharinen P, Bry M and Alitalo K: How do angiopoietins Tie with vascular endothelial growth factors? Curr Opin Hematol 17: 198-205, 2010.

55. Chen Y, Song Y, Du W, Gong L, Chang H and Zou Z: Tumor-associated macrophages: An accomplice in solid tumor progression. J Biomed Sci 26: 78, 2019.

56. Mazzieri R, Pucci F, Moi D, Zonari E, Ranghetti A, Berti A Politi LS, Gentner B, Brown JL, Naldini L and De Palma M: Targeting the ANG2/TIE2 axis inhibits tumor growth and metastasis by impairing angiogenesis and disabling rebounds of proangiogenic myeloid cells. Cancer Cell 19: 512-526, 2011

57. Dirkx AE, Oude Egbrink MG, Wagstaff J and Griffioen AW: Monocyte/macrophage infiltration in tumors: Modulators of angiogenesis. J Leukoc Biol 80: 1183-1196, 2006.

58. Chaffer CL and Weinberg RA: A perspective on cancer cell metastasis. Science 331: 1559-1564, 2011.

59. Wyckoff J, Wang W, Lin EY, Wang Y, Pixley F, Stanley ER, Graf T, Pollard JW, Segall J and Condeelis J: A paracrine loop between tumor cells and macrophages is required for tumor cell migration in mammary tumors. Cancer Res 64: 7022-7029, 2004.

60. Gocheva V, Wang HW, Gadea BB, Shree T, Hunter KE, Garfall AL, Berman T and Joyce JA: IL-4 induces cathepsin protease activity in tumor-associated macrophages to promote cancer growth and invasion. Genes Dev 24: 241-255, 2010.

61. DeNardo DG, Barreto JB, Andreu P, Vasquez L, Tawfik D, Kolhatkar N and Coussens LM: CD4(+) T cells regulate pulmonary metastasis of mammary carcinomas by enhancing protumor properties of macrophages. Cancer Cell 16: 91-102, 2009. 
62. Hernandez L, Smirnova T, Kedrin D, Wyckoff J, Zhu L, Stanley ER, Cox D, Muller WJ, Pollard JW, Van Rooijen N and Segall JE: The EGF/CSF-1 paracrine invasion loop can be triggered by heregulin beta 1 and CXCL12. Cancer Res 69 : 3221-3227, 2009.

63. Kim S, Takahashi H, Lin WW, Descargues P, Grivennikov S, Kim Y, Luo JL and Karin M: Carcinoma-produced factors activate myeloid cells through TLR2 to stimulate metastasis. Nature 457: 102-106, 2009.

64. Yan D, Wang HW, Bowman RL and Joyce JA: STAT3 and STAT6 signaling pathways synergize to promote cathepsin secretion from macrophages via IRE1 $\alpha$ activation. Cell Rep 16: 2914-2927, 2016.

65. Quintero-Fabián S, Arreola R, Becerril-Villanueva E, Torres-Romero JC, Arana-Argáez V, Lara-Riegos J, Ramírez-Camacho MA and Alvarez-Sánchez ME: Role of matrix metalloproteinases in angiogenesis and cancer. Front Oncol 9: 1370, 2019.

66. Jiang D, Liang $\mathbf{J}$ and Noble PW: Hyaluronan as an immune regulator in human diseases. Physiol Rev 91: 221-264, 2011.

67. Wang N, Liu W, Zheng Y, Wang S, Yang B, Li M, Song J, Zhang F, Zhang X, Wang Q and Wang Z: CXCL1 derived from tumor-associated macrophages promotes breast cancer metastasis via activating NF- $\mathrm{kB} / \mathrm{SOX} 4$ signaling. Cell Death Dis 9: $880,2018$.

68. Izumi K and Mizokami A: Suppressive role of androgen/androgen receptor signaling via chemokines on prostate cancer cells. J Clin Med 8: 354, 2019.

69. Wang D, Sun H, Wei J, Cen B and DuBois RN: CXCL1 is critical for premetastatic niche formation and metastasis in colorectal cancer. Cancer Res 13: 3655-3665, 2017.

70. Kawano M, Mabuchi S, Matsumoto Y, Sasano T, Takahashi R, Kuroda H, Kozasa K, Hashimoto K, Isobe A, Sawada K, et al: The significance of G-CSF expression and myeloid-derived suppressor cells in the chemoresistance of uterine cervical cancer. Sci Rep 5: 18217, 2015.

71. Rőszer T: Understanding the mysterious M2 macrophage through activation markers and effector mechanisms. Mediators Inflamm 2015: 816460, 2015.

72. Okeke EB and Uzonna JE: The pivotal role of regulatory T cells in the regulation of innate immune cells. Front Immunol 10: 680, 2019.

73. Hoves S, Ooi CH, Wolter C, Sade H, Bissinger S, Schmittnaegel M, Ast O, Giusti AM, Wartha K, Runza V, et al: Rapid activation of tumor-associated macrophages boosts preexisting tumor immunity. J Exp Med 215: 859-876, 2018.

74. Ma X, Yan W, Zheng H, Du Q, Zhang L, Ban Y, Li N and Wei F: Regulation of IL-10 and IL-12 production and function in macrophages and dendritic cells 4: F1000 Faculty Rev-1465, 2015.

75. Kanamori M, Nakatsukasa H, Okada M, Lu Q and Yoshimura A: Induced regulatory $\mathrm{T}$ Cells: Their development, stability, and applications. Trends Immunol 37: 803-811, 2016.

76. Chanmee T, Ontong P, Konno K and Itano N: Tumor-associated macrophages as major players in the tumor microenvironment. Cancers (Basel) 6: 1670-1690, 2014

77. Zhang J, Shi Z, Xu X, Yu Z and Mi J: The influence of microenvironment on tumor immunotherapy. FEBS J 286: 4160-4175, 2019.

78. Czystowska-Kuzmicz M, Sosnowska A, Nowis D, Ramji K, Szajnik M, Chlebowska-Tuz J, Wolinska E, Gaj P, Grazul M, Pilch Z, et al: Small extracellular vesicles containing arginase-1 suppress T-cell responses and promote tumor growth in ovarian carcinoma. Nat Commun 10: 3000, 2019.

79. Pathria P, Louis TL and Varner JA: Targeting tumor-associated macrophages in cancer. Trends Immunol 40: 310-327, 2019.

80. Zhang D, Shi R, Xiang W, Kang X, Tang B, Li C, Gao L, Zhang X, Zhang L, Dai R and Miao H: The Agpat4/LPA axis in colorectal cancer cells regulates antitumor responses via p38/p65 signaling in macrophages. Signal Transduct Target Ther 5: 24, 2020.

81. Vinogradov S, Warren G and Wei X: Macrophages associated with tumors as potential targets and therapeutic intermediate. Nanomedicine (Lond) 9: 695-707, 2014.
82. Nywening TM, Belt BA, Cullinan DR, Panni RZ, Han BJ, Sanford DE, Jacobs RC, Ye J, Patel AA, Gillanders WE, et al: Targeting both tumour-associated CXCR2 ${ }^{+}$neutrophils and CCR $2^{+}$macrophages disrupts myeloid recruitment and improves chemotherapeutic responses in pancreatic ductal adenocarcinoma. Gut 67: 1112-1123, 2018.

83. Lee C, Jeong H, Bae Y, Shin K, Kang S, Kim H, Oh J and Bae H: Targeting of M2-like tumor-associated macrophages with a melittin-based pro-apoptotic peptide. J Immunother Cancer 7: $147,2019$.

84. Andersen MN, Etzerodt A, Graversen JH, Holthof LC, Moestrup SK, Hokland $M$ and Møller HJ: STAT3 inhibition specifically in human monocytes and macrophages by CD163-targeted corosolic acid-containing liposomes. Cancer Immunol Immunother 68: 489-502, 2019

85. Wanderley CW, Colón DF, Luiz JPM, Oliveira FF, Viacava PR, Leite CA, Pereira JA, Silva CM, Silva CR, Silva RL, et al: Paclitaxel reduces tumor growth by reprogramming tumor-associated macrophages to an M1 profile in a TLR4-dependent manner. Cancer Res 78: 5891-5900, 2018

86. Locatelli SL, Careddu G, Serio S, Consonni FM, Maeda A, Viswanadha S, Vakkalanka S, Castagna L, Santoro A, Allavena P, et al: Targeting cancer cells and tumor microenvironment in preclinical and clinical models of Hodgkin lymphoma using the dual PI3Kס/ $\gamma$ inhibitor RP6530. Clin Cancer Res 25: 1098-1112, 2019

87. Tan HY, Wang N, Man K, Tsao SW, Che CM and Feng Y: Autophagy-induced RelB/p52 activation mediates tumour-associated macrophage repolarisation and suppression of hepatocellular carcinoma by natural compound baicalin. Cell Death Dis 6: e1942, 2015.

88. Medler TR, Murugan D, Horton W, Kumar S, Cotechini T, Forsyth AM, Leyshock P, Leitenberger JJ, Kulesz-Martin M, Margolin AA, et al: Complement C5a fosters squamous carcinogenesis and limits $t$ cell response to chemotherapy. Cancer Cell 34: 561-578.e6, 2018

89. Guerriero JL, Sotayo A, Ponichtera HE, Castrillon JA, Pourzia AL, Schad S, Johnson SF, Carrasco RD, Lazo S, Bronson RT, et al: Class IIa HDAC inhibition reduces breast tumours and metastases through anti-tumour macrophages. Nature 543: 428-432, 2017

90. Zhang W, Wang M, Tang W, Wen R, Zhou S, Lee C, Wang H, Jiang W, Delahunty IM, Zhen Z, et al: Nanoparticle-laden macrophages for tumor-tropic drug delivery. Adv Mater 30: e1805557, 2018.

91. Choi J, Kim HY, Ju EJ, Jung J, Park J, Chung HK, Lee JS, Lee JS, Park HJ, Song SY, et al: Use of macrophages to deliver therapeutic and imaging contrast agents to tumors. Biomaterials 33: 4195-4203, 2012

92. Opperman KS, Vandyke K, Clark KC, Coulter EA, Hewett DR, Mrozik KM, Schwarz N, Evdokiou A, Croucher PI, Psaltis PJ, et al: Clodronate-liposome mediated macrophage depletion abrogates multiple myeloma tumor establishment in vivo. Neoplasia 21: 777-787, 2019.

93. Zhang F, Parayath NN, Ene CI, Stephan SB, Koehne AL, Coon ME, Holland EC and Stephan MT: Genetic programming of macrophages to perform anti-tumor functions using targeted mRNA nanocarriers. Nat Commun 10: 3974, 2019.

94. Buhtoiarov IN, Sondel PM, Wigginton JM, Buhtoiarova TN, Yanke EM, Mahvi DA and Rakhmilevich AL: Anti-tumour synergy of cytotoxic chemotherapy and anti-CD40 plus CpG-ODN immunotherapy through repolarization of tumour-associated macrophages. Immunology 132: 226-239, 2011.

95. Di Caro G, Cortese N, Castino GF, Grizzi F, Gavazzi F, Ridolfi C, Capretti G, Mineri R, Todoric J, Zerbi A, et al: Dual prognostic significance of tumour-associated macrophages in human pancreatic adenocarcinoma treated or untreated with chemotherapy. Gut 65: 1710-1720, 2016.

This work is licensed under a Creative Commons Attribution-NonCommercial-NoDerivatives 4.0 International (CC BY-NC-ND 4.0) License. 